\title{
Effect of nicotine on cariogenic virulence of Streptococcus mutans
}

Authors: Mingyun $\mathrm{Li}^{1,2^{*}}$, Ruijie Huang ${ }^{1,2,3}$, Xuedong Zhou ${ }^{1}$, Wei Qiu ${ }^{1}$, Xin $\mathrm{Xu}^{1}$, and Richard L. Gregory $^{2,4 *}$

\section{Affiliation and Address:}

${ }^{1}$ State Key Laboratory of Oral Diseases, West China Hospital of Stomatology, Sichuan University, NO.14, 3rd Section of Ren Min Nan Rd, Chengdu, Sichuan 610041, China

${ }^{2}$ Department of Biomedical and Applied Sciences, School of Dentistry, Indiana University, 1121 W. Michigan Street, Indianapolis, IN 46202, United States

${ }^{3}$ Department of Pediatric Dentistry, West China Hospital of Stomatology, Sichuan University, Chengdu, Sichuan 610041, China

${ }^{4}$ Department of Pathology and Laboratory Medicine, School of Medicine, Indiana University Indianapolis, IN 46202, United States

Running Title: Nicotine affects pathogenic of S. mutans

\section{Corresponding author:}

Mingyun Li, D.D.S., Ph.D. Mailing address: State Key Laboratory of Oral diseases, West China Hospital of Stomatology, Sichuan University, No. 14 Renmin South Road, Chengdu, China 610041 (email): limingyun@scu.edu.cn;

Richard L. Gregory

Indiana University School of Dentistry, 1121 W. Michigan Street, Indianapolis, IN 46202, United States, Tel: (317) 274-9949/ Fax: (317) 278-1411

(email): rgregory@iu.edu

This is the author's manuscript of the article published in final edited form as:

Li, M., Huang, R., Zhou, X., Qiu, W., Xu, X., \& Gregory, R. L. (2016). Effect of nicotine on cariogenic virulence of Streptococcus mutans. Folia Microbiologica, 61(6), 505-512. https://doi.org/10.1007/s12223-016-0465-8 


\begin{abstract}
Nicotine has well documented effects on the growth and colonization of Streptococcus mutans. This study attempts to investigate the effects of nicotine on pathogenic factors of $S$. mutans, such as the effect on biofilm formation and viability, expression of pathogenic genes, and metabolites of $S$. mutans. The results demonstrated that addition of nicotine did not significantly influence the viability of $S$. mutans cells. The biofilms became increasingly compact as the concentrations of nicotine increased. The expression of virulence genes, such as ldh and phosphotransferase system (PTS) associated genes were up-regulated and $n l m C$ was upregulated significantly, while $\mathrm{ft} f$ was down-regulated. The lactate concentration of $S$. mutans grown in $1 \mathrm{mg} / \mathrm{ml}$ of nicotine was increased up to 2 fold over either biofilm or planktonic cells grown without nicotine. Changes in the metabolites involved in central carbon metabolism from sucrose indicated that most selected metabolites were detectable and influenced by increased concentrations of nicotine. This study demonstrated that nicotine can influence the pathogenicity of S. mutans, and may lead to increased dental caries through the production of more lactate and the up-regulation of virulence genes.
\end{abstract}

Keywords

Streptococcus mutans; dental caries; nicotine; LC-MS/MS 


\section{Introduction}

Dental caries is one of the most common chronic infectious disease in humans (Petersen et al. 2005). The metabolism of sucrose is a common factor in dental plaque and plays a key role in the formation of caries. Sucrose is the main cariogenic carbohydrate (Burt 1993; Woodward and Walker 1994), and its metabolites, such as organic acids and polysaccharides, influence the development of dental caries. The prevalence of organic acids in dental plaque is the central factor in caries formation. Essentially, the production of lactic acid by acidogenic oral microflora causes demineralization of crystalline calcium and phosphate present in hydroxyapatite that comprises tooth enamel (Weatherell 1975). When the frequency and rate of acid production exceeds the natural remineralization of the teeth (Von Der Fehrfr 1965), demineralization occurs, resulting in the subsequent development of caries, provided the $\mathrm{pH}$ remains below a 'critical' value of approximately 5.5 for a sufficient length of time (Hamilton 2000; Takahashi and Nyvad 2008). The process of sucrose metabolism is very complex in dental biofilms.

Streptococcus mutans is a Gram positive bacterium and is considered the major cariogenic agent in humans. S. mutans has the ability to alter the ecology of dental plaque primarily due to its acidic metabolic products (Loesche 1986). In addition, S. mutans may express certain virulence factors in order to maintain its ecological niche in the oral cavity (Svensater et al. 1997). Three major cariogenic factors associated with S. mutans include adhesion, acidogenicity (the ability to produce acid) and aciduricity (the ability to tolerate an acidic environment) (Banas 2004). In the 1940s, Stephan conducted research on the $\mathrm{pH}$ of the oral microbiota in response to sugar exposure, where he reported that the $\mathrm{pH}$ of plaque was significantly reduced by the organic acids produced in response to the sugar (Stephan 1940; Stephan 1944). 
It is well documented that tobacco smoking affects health. Historically, the most common systemic diseases related to smoking are lung cancer and cardiovascular disease (Wellmann 1964). Although the relationship between caries and smoking has been documented (Carbajosa Garcia and Llena Puy 2011; Rooban et al. 2011; Tomar and Winn 1999), very few studies have focused on understanding why smokers or children exposed to environmental tobacco smoke are prone to the development of caries. In the past, most tobacco research has focused on the relationship between smoking and periodontal disease, while more and more studies have established that smoking affects caries. Caries development is considered to be related to an imbalance of the oral microflora. Therefore, it is very important to study the effect of tobacco use on the oral microbial balance and subsequently investigate the relationship between tobacco use and the formation of caries. Our previous study demonstrated that nicotine could increase not only the growth of $S$. mutans, but also the overall metabolic activity of cells growing in a biofilm (Huang et al. 2012). In this study, we use LC-MS/MS to analyze sucrose metabolism of $S$. mutans after exposure to nicotine. Our results provide answers for long-standing questions, such as why passive smokers have increased dental caries, and provide new insights into the ability of nicotine to regulate metabolic pathways in S. mutans resulting in increased lactate production and caries formation. 


\section{Materials and Methods}

\section{Bacterial Growth and Preparation}

Streptococcus mutans UA159 (ATCC 700610) was stored at $-80^{\circ} \mathrm{C}$ in Todd-Hewitt broth (THB, Acumedia, Baltimore, MA) supplemented with 10\% glycerol until used for the study. S. mutans cultures were grown in Tryptic Soy broth (TSB, Difco, Detroit, MI) in $5 \% \mathrm{CO}_{2}$ at $37^{\circ} \mathrm{C}$ without agitation.

\section{Biofilm Viability Analysis}

Fresh whole saliva was collected from three individuals who had no history of antibiotic or antimicrobial toothpaste usage for the previous 6 months and pooled after IRB approval and informed consent was obtained. Overnight cultures of S. mutans were inoculated on salivacoated glass coverslips $\left(1 \times 10^{6} \mathrm{CFU} / \mathrm{ml}\right)$ prepared as described earlier (Li et al. 2014), but modified by coating with a pool of undiluted filter-sterilized saliva for $30 \mathrm{~min}$ at $37^{\circ} \mathrm{C}$ and placed in separate wells of sterile 24 well tissue culture plates. Different nicotine concentrations $(0,1$, and $2 \mathrm{mg} / \mathrm{ml}$ ) in $2 \mathrm{ml}$ of TSBS (TSB containing $1 \%$ sucrose) media were added to each culture well, inoculated with $S$. mutans $(100 \mu \mathrm{l})$ and the plate was incubated at $37^{\circ} \mathrm{C}$ in $5 \% \mathrm{CO}_{2}$. After $24 \mathrm{~h}$ of growth, planktonic and loosely attached cells were removed and biofilms were stained using a BacLight live/dead kit (Molecular Probes, Eugene, OR, USA) (Zhou et al. 2014). Live bacteria were stained with SYTO 9, while bacteria with compromised membranes were stained with propidium iodide (PI). Biofilm images were captured using confocal laser scanning microscope (CLSM, Leica). Each biofilm was scanned at five randomly selected positions.

\section{Scanning Electronic Microscopy}


The architecture of $S$. mutans biofilms was examined by scanning electron microscopy (SEM; FEI, Hillsboro, OR, USA). A saliva-coated glass coverslip was placed in each well of a sterile 24-well tissue culture and an overnight culture of S. mutans $\left(1 \times 10^{6} \mathrm{CFU} / \mathrm{mL}\right)$ in TSBS and different concentrations of nicotine were added. After $24 \mathrm{~h}$ of growth, planktonic and loosely attached cells were removed and biofilms were fixed with glutaraldehyde at room temperature for $12 \mathrm{~h}$, then serially dehydrated in ethanol and sputter-coated with gold. Specimens were examined at 2,000,5,000,10,000, and 20,000× magnifications. Representative images were obtained.

\section{LC-MS/MS Sample Preparation}

Briefly, S. mutans was grown in the presence of different nicotine concentrations $(0,1$ and 4 $\mathrm{mg} / \mathrm{ml}$ ) for both sucrose-induced biofilm formation and planktonic assays.

For sucrose-induced biofilm formation, the overnight cultures were diluted 1:100 in TSBS containing different concentrations of nicotine $(0,1$ and $4 \mathrm{mg} / \mathrm{ml})$, and then incubated in flasks (250.0 ml, $75.0 \mathrm{~cm}^{2}$ ) (Fisher Scientific Co., Pittsburgh, PA) at $37^{\circ} \mathrm{C}$ in $5 \% \mathrm{CO}_{2}$ for $24 \mathrm{~h}$. The biofilms were washed three times with sterile $\mathrm{dH}_{2} \mathrm{O}$ and about $1 \mathrm{~g}$ (wet weight) biofilm cells were collected by centrifugation.

For planktonic cells, the overnight cultures were diluted 1:100 in TSB without nicotine and incubated in flasks for approximately $10 \mathrm{~h}$ (log phase) at which point the planktonic cells were harvested.

After collection of the cells, the process of lysing the cells was determined as previously described with some modification (Takahashi et al. 2010). $16 \mathrm{ml}$ of ice-cold methanol, $16 \mathrm{ml}$ of chloroform and $10 \mathrm{ml}$ of ice-cold Milli-Q water were added to each $1 \mathrm{~g}$ cell pellet and the 
suspension was vortexed for about 1 min to lyse all the cells. The preparation was centrifuged at $3,750 \mathrm{rpm}$ and $4^{\circ} \mathrm{C}$ for $10 \mathrm{~min}$, and the upper layer transferred to a new tube (water: methanol phase). The aqueous top layer was evaporated to dryness using a Speedvac (SPD111V, Thermo Scientific, America). The samples were subsequently stored at $-80^{\circ} \mathrm{C}$ until analyzed.

\section{LC-MS/MS Conditions}

Samples were analyzed according to Jannasch et al. (Jannasch et al. 2011). Each sample was reconstituted in $500 \mu \mathrm{L}$ of deionized water and vortexed for 20 minutes. The samples were then centrifuged at 4,000 rpm for 5 minutes and $100 \mu \mathrm{L}$ of the supernatant was used for analysis. Each sample was derivatized with 10 ul of $6 \mathrm{M}$ aniline $\mathrm{pH} 4.5$ plus 10 ul of $\mathrm{N}$-(3Dimethylaminopropyl)- $N^{\prime}$-ethylcarbodiimide hydrochloride $(2 \mathrm{mg} / 10 \mu \mathrm{L}$ water). The reaction time was 2 hours at room temperature and stopped by the addition of $3 \mu \mathrm{L}$ of triethylamine. At the same time, a standard mixture in water was derivatized with ${ }^{13} \mathrm{C}_{6}$-aniline solution. Once the reactions were complete, the sample and standard solution were mixed at a ratio of 1:1 (v/v) and immediately analyzed by LC-MS/MS on an Agilent 6460 QQQ coupled to an Agilent 1200 series LC pump. The LC utilized an Agilent Eclipse XDB-C8 column $(2.1 \times 150 \mathrm{~mm}, 3.5 \mu \mathrm{m})$ with 10 $\mathrm{mM}$ ammonium bicarbonate at $\mathrm{pH} 4.5$ adjusted with acetic acid as buffer $\mathrm{A}$ and acetonitrile as buffer B. The linear gradient was as follows: time $0,0 \% \mathrm{~B}$; time 3 minutes, $0 \% \mathrm{~B}$; time 14 minutes, $98 \% \mathrm{~B}$; time 15 minutes, $98 \% \mathrm{~B}$; time 17 minutes, $0 \% \mathrm{~B}$; and time 20 minutes, $0 \% \mathrm{~B}$. The flow rate was $0.3 \mathrm{~mL} /$ minute. The MS conditions were as follows: gas temperature $300^{\circ} \mathrm{C}$, gas flow $10 \mathrm{~L} /$ minute, nebulizer pressure $35 \mathrm{psi}$, sheath gas temperature $250^{\circ} \mathrm{C}$, sheath gas flow $7 \mathrm{~L} /$ minute, capillary voltage $3000 \mathrm{~V}$, and nozzle voltage $1000 \mathrm{~V}$. The data were acquired in negative ESI mode using multiple reaction monitoring (MRM). 
In this study, several metabolites were targeted for identification. Six different metabolites from the EMP pathway were detected: glucose 6-phosphate (G6P), fructose 6-phosphate (F6P), dihydroxyacetone phosphate (DHAP), 3-phosphoglycerate (3PG), phosphoenolpyruvate (PEP) and pyruvate, while only 6-phosphogluconate (6PG) was targeted as a key metabolite of the pentose phosphate pathway. Four TCA cycle metabolites were targeted: acetyl CoA, succinate, fumarate and malate.

\section{Quantitative Real-time PCR}

qRT-PCR was used to quantify S. mutans nlmC, $\operatorname{ldh}$, $\mathrm{ftf}$ (associated with pathogenicity of $S$. mutans) (Salem et al. 1985; Senadheera et al. 2012; Shiroza and Kuramitsu 1988), ptsI, ptsH, scrA, scrB and ptsK (associated with phosphotransferase system, PTS) (Ajdic et al. 2002; Zeng and Burne 2013), mRNA expression, with 16S rRNA as an internal control. All the primers used are shown in Table 1. Total bacterial RNA isolation, purification, and cDNA reverse transcription were performed as previously described (Xu et al. 2011). Threshold cycle values (CT) were determined, and the data was analyzed by Bio-Rad CFX Manager software (version 2.0 ) according to the $2^{-\Delta \Delta \mathrm{CT}}$ method.

\section{Statistical Analysis}

Differences in the amounts of each metabolite between the nicotine-treated experimental and non-treated control groups were analyzed by SPSS software (version 16.0, Chicago, Ill., USA). Results are presented as means with the standard deviation. One-way ANOVA with post hoc tests were used to compare multiple means and a paired $t$ test was used to compare LCMS/MS data. 


\section{Results}

The results demonstrate that the addition of nicotine at 0,1 and $2 \mathrm{mg} / \mathrm{ml}$ does not significantly influence the viability of S. mutans cells (Fig. 1) as determined by the relative number of green live cells. However, the SEM results indicated that $S$. mutans biofilms grew in a more compact form as the concentration of nicotine increased (Fig. 2). There was an obvious increase in the mass of $S$. mutans biofilms when grown in the presence of 1 and $2 \mathrm{mg} / \mathrm{ml}$ of nicotine compared to control cultures. The biofilm structures appeared denser and the bacterial density was increased as the concentration of nicotine increased.

In this study, several metabolites were targeted for identification. Of the metabolites in the Embden-Meyerhof-Parnas (EMP) pathway, only fructose 6-phosphate (F6P) levels were significantly different between planktonic and biofilm cells, both grown without nicotine. Changes in other EMP pathway metabolites, such as glucose 6-phosphate (G6P), 3phosphoglycerate (3PG), pyruvate and phosphoenolpyruvate (PEP) were not significantly altered (Fig. 3A). When biofilm cells were exposed to $1 \mathrm{mg} / \mathrm{ml}$ of nicotine only $3 \mathrm{PG}$ from the EMP pathway was significantly increased from biofilm grown without nicotine (Fig. 3B), while other EMP pathway metabolites, G6P, F6P, PEP and pyruvate were not significantly changed. A comparison of biofilm cells grown in the presence of $4 \mathrm{mg} / \mathrm{ml}$ nicotine and control biofilm cells demonstrated that EMP pathway metabolites, F6P, 3PG and PEP increased with $4 \mathrm{mg} / \mathrm{ml}$ of nicotine, while G6P and pyruvate both decreased, although none of these changes were significant (Fig. 3C). A ratio comparison of metabolites from biofilm cells grown in the presence or absence of nicotine demonstrates the effect of nicotine on the metabolome profile more clearly (Fig. 3D). In the presence of $1 \mathrm{mg} / \mathrm{ml}$ of nicotine, G6P, F6P, 3PG, PEP and pyruvate in the EMP pathway and succinate, fumarate and malate in the tricarboxylic (TCA) cycle increased over the 
control biofilm, while dihydroxyacetone phosphate (DHAP) in the EMP pathway and 6phosphogluconate (6PG) (data not shown) in the pentose phosphate pathway decreased. In the presence of $4 \mathrm{mg} / \mathrm{ml}$ of nicotine, 3PG, PEP and pyruvate in the EMP pathway, 6PG (data not shown) in the pentose phosphate pathway and succinate, fumarate and malate in the TCA cycle increased, while G6P and DHAP in the EMP pathway decreased.

Lactate was detected in all cell samples (Table 2). In planktonic and biofilm cells grown without nicotine, approximately the same amount of lactate was detected. However, lactate production was significantly increased when the cells were exposed to $1 \mathrm{mg} / \mathrm{ml}$ nicotine, and decreased in the presence of $4 \mathrm{mg} / \mathrm{ml}$ nicotine compared to biofilms grown without nicotine, although this was not significantly different.

We investigated the expression of $S$. mutans virulence genes, such as $l d h, n l m C$ and $f t f$, when the cells were grown in presence or absence of nicotine (Fig 4). Idh and $n l m C$ were upregulated in the presence of nicotine $(\mathrm{P}>0.05)$, however, only $n \operatorname{lm} C$ demonstrated a significant change in expression $(\mathrm{P}<0.05)$. $f t f$ was down-regulated, but not significantly $(\mathrm{P}>0.05)$. All PTS associated genes (ptsH, ptsI, ptsK, scrA and scrB) were up-regulated but only ptsH and scrA exhibited significant differences $(\mathrm{P}<0.05)$. 


\section{Discussion}

Carbohydrate metabolism is a key survival strategy for S. mutans and current knowledge surrounding sugar metabolism of this organism suggests that $S$. mutans is capable of metabolizing a wider variety of carbohydrates than any other Gram-positive organism sequenced to date. Sucrose is among the most cariogenic carbohydrates, and exposure to sucrose influences the development of caries in multiple ways. In this study we selected $1 \%$ sucrose as the carbohydrate source for the S. mutans when growing as a biofilm. Sucrose is a substrate for glucosyltransferase (GTF), an enzyme that is either cell-associated or secreted by S. mutans. Our previous studies demonstrated that nicotine can upregulate gtf expression (Li et al. 2013), and also enhance the production of exopolysaccharide (EPS) in S. mutans (Li et al. 2014). GTF releases free fructose and glucose and is considered the primary etiologic factor in S. mutansderived human caries. In the current study, nicotine upregulated PTS-associated genes, suggesting that more sucrose was transported into the bacterial cell to be metabolized into lactic acid and other sucrose metabolites. Through the glycolytic pathway, metabolism of sucrose can release the same amount of organic acid as glucose, while metabolism of fructose releases significantly less organic acid than sucrose. This study demonstrates the effect that different nicotine concentrations have on the metabolism of sucrose in S. mutans biofilm and planktonic growth, with a focus on metabolites of the EMP and pentose phosphate pathways and the TCA cycle.

When there is abundant sucrose available to $S$. mutans, glycolytic metabolism will increase and the cell produces much more lactate to decrease the $\mathrm{pH}$ of the biofilm. Glycolytic enzymes involved in metabolic pathways function over a wide $\mathrm{pH}$ range, with activity down to $\mathrm{pH} 4.0$ (Bender et al. 1985; Hamilton and Buckley 1991), which is well below the critical pH value of 
5.5 for the initiation of caries. Furthermore, it has been demonstrated that in most instances, the rate of acid production by S. mutans over a $\mathrm{pH}$ range of 5.0-7.0 surpasses the rate of acid production by other oral streptococci (de Soet et al. 2000). This helps to explain the rapid pH drop of dental plaque harboring S. mutans in the presence of sucrose (Jensen et al. 1982).

In this study, we determined the amount of lactate produced by S. mutans cells growing in planktonic culture without nicotine and biofilm with 0,1 or $4 \mathrm{~g} / \mathrm{ml}$ nicotine (Table 2). When planktonic and biofilm cells grown without nicotine were compared, there was no significant difference in the amount of lactate produced. However, when nicotine was added to the culture (i.e., $1 \mathrm{mg} / \mathrm{ml}$ ), the amount of lactate in biofilm cells was significantly higher (approximately 2 fold) than in planktonic or biofilm cells without nicotine.

The acidification of the local environment by metabolic end products is one of the main weapons to inhibit many commensal bacteria, enabling S. mutans to maintain its niche and causing dental caries in the host. Since no difference in overall cell yield was observed in the lower $\mathrm{pH}$-adapted cultures, these results demonstrated that $\mathrm{S}$. mutans can alter its metabolism in response to an altered external $\mathrm{pH}$ (Hamilton and Ellwood 1978). In addition, it was shown that both the $\mathrm{pH}$ optimum of glucose uptake and glycolysis shifted to lower values in accordance with lower extracellular $\mathrm{pH}$, further supporting the ability of S. mutans to alter its metabolic activity as an acid-adaptive response (Hamilton and Buckley 1991). Furthermore, synthesis of branched amino acids may also reduce the $\mathrm{H}^{+}$concentration in the cytoplasm through the consumption of nicotinamide adenine dinucleotide phosphate (NADP) (an intermediate step in this anabolic pathway) and by removing reducing equivalents in the form of pyruvate and 2oxobutanoate (Len et al. 2004). 
The fermentation of carbohydrates by S. mutans is the principal source of energy for the organism. The complete glycolytic pathway has been described in S. mutans UA159, and it leads to the production of pyruvate that is then reduced to various fermentation products (lactic acid, formate, ethanol, and acetate). Figure 3A indicates that the amount of all detected metabolites without nicotine in biofilm cells was generally lower than in planktonic cells except for pyruvate, while F6P was significantly decreased. However, the amount of lactate in biofilm cells grown in $1 \mathrm{mg} / \mathrm{ml}$ nicotine was higher. These observations indicate that $S$. mutans is able to alter its metabolic activity in response to external $\mathrm{pH}$ fluctuations even when growing as a biofilm. When S. mutans was cultured in TSBS with $1 \mathrm{mg} / \mathrm{ml}$ nicotine, the levels of the majority of the detected biofilm metabolites increased compared to biofilms grown without nicotine, especially 3PG. These results suggest that nicotine can increase the metabolic activity of S. mutans. Nicotine also appears to alter the glycolytic pathway by inhibiting the production of DHAP, increasing the conversion of F6P to G3P, significantly increasing the amount of 3PG, and increasing the activity of lactate dehydrogenase. Most importantly, nicotine increases the production of lactic acid, leading to a reduction in $\mathrm{pH}$ and preparing the environment for the development of dental caries.

In this study, addition of $4 \mathrm{mg} / \mathrm{ml}$ of nicotine to the biofilm cultures seemed to have no influence on both the metabolites and the production of lactate compared to biofilms grown without nicotine (Fig. 3C, and Table 2). However, the amount of 3PG and PEP was higher in biofilm cells with $4 \mathrm{mg} / \mathrm{ml}$ of nicotine than in biofilms without nicotine, while the amount of pyruvate was slightly lower. This suggests that higher concentrations of nicotine may repress the conversion of PEP to pyruvate, additionally inhibiting the activity of lactate dehydrogenase, leading to decreased lactate production at higher nicotine levels. 
Streptococcus mutans possesses an incomplete tricarboxylic acid (TCA) cycle (Cvitkovitch et al. 1997). In this study, three TCA cycle metabolites (succinate, FUM and MAL) were detected. The amount of these metabolites in the TCA cycle was much lower than the EMP pathway metabolites. This confirms that the glycolytic pathway is the main carbohydrate metabolic pathway in S. mutans. The primary role of the existing TCA cycle enzymes is most likely the synthesis of amino acid precursors (Cvitkovitch et al. 1997). Most S. mutans strains can grow in vitro on minimal media supplemented with only a few amino acids (Terleckyj and Shockman 1975), and several strains can be cultured anaerobically with ammonia as the sole nitrogen source (St Martin and Wittenberger 1980).

The present study revealed that metabolome analysis is able to detect $S$. mutans metabolic regulation in in vitro. S. mutans biofilms grown in different concentrations of nicotine demonstrate variable effects on the metabolic activity of S. mutans. However, our metabolome analysis suggests that $1 \mathrm{mg} / \mathrm{ml}$ of nicotine could increase the metabolic activity of $S$. mutans, increasing the majority of glycolytic pathway metabolites, resulting in significantly increased lactate, leading to a drop in external $\mathrm{pH}$ and possibly contributing to caries formation. Metabolome analyses of biofilms can be applied to monitoring the efficacy of dietary components and medications on the biofilm, leading to the development of effective plaque control methods. The metabolic analysis in the present study confirms that nicotine enhances $S$. mutans biofilm formation. The study also indicates that nicotine affects regulation of the sucrose metabolic pathway, especially lactate production, which is closely related to the development of caries. The results suggest one possible reason that smokers and passive smokers have increased risk of developing dental caries. The effects of nicotine on S. mutans sugar metabolism and acid production confirms the mechanistic relationship between smoking and caries. 


\section{Acknowledgements}

Thanks to Amber Jannasch from Purdue University for the detecting metabolites of $S$. mutans by LC-MS/MS. This study was partially supported by the NIH grants HL098960 and DE020614, the Indiana University Purdue University Indianapolis Tobacco Cessation and Biobehavioral Group (R.L.G) and National Natural Science Foundation of China (81400501 to M.L. and 81430011 to X.Z.); the International Science and Technology Cooperation Program of China 2014DFE30180 (X.Z.); and the Special Fund of State Key Laboratory of Oral Diseases, Sichuan University (SKLOD201525 to M.L.). The authors declare no potential conflict of interest with respect to the authorship and/or publication of this article. 


\section{References}

Ajdic D et al. (2002) Genome sequence of Streptococcus mutans UA159, a cariogenic dental pathogen Proceedings of the National Academy of Sciences of the United States of America 99:14434-14439 doi:10.1073/pnas.172501299

Banas JA (2004) Virulence properties of Streptococcus mutans. Front Biosci 9:1267-1277 doi:10.2741/1305

Bender GR, Thibodeau EA, Marquis RE (1985) Reduction of acidurance of streptococcal growth and glycolysis by fluoride and gramicidin. J Dent Res 64:90-95 doi:10.1177/00220345850640021701

Burt BA (1993) Relative consumption of sucrose and other sugars: has it been a factor in reduced caries experience? Caries Res 27:56-63

Carbajosa Garcia S, Llena Puy C (2011) Relationship between tobacco smoke and dental caries in school children at the Valencian Country. Rev Esp Salud Publica 85:217225 doi:10.1590/S1135-57272011000200009

Cvitkovitch DG, Gutierrez JA, Bleiweis AS (1997) Role of the citrate pathway in glutamate biosynthesis by Streptococcus mutans. J Bacteriol 179:650-655

de Soet JJ, Nyvad B, Kilian M (2000) Strain-related acid production by oral streptococci. Caries Res 34:486-490 doi:10.1159/000016628

Hamilton IR (2000) Ecological basis for dental caries. Oral Bacterial Ecology: The molecular Basis. Horizon Scientific Press,

Hamilton IR, Buckley ND (1991) Adaptation by Streptococcus mutans to acid tolerance. Oral Microbiol Immunol 6:65-71 doi:10.1111/j.1399-302X.1991.tb00453.x

Hamilton IR, Ellwood DC (1978) Effects of fluoride on carbohydrate metabolism by washed cells of Streptococcus mutans grown at various $\mathrm{pH}$ values in a chemostat. Infect Immun 19:434-442

Huang R, Li M, Gregory RL (2012) Effect of nicotine on growth and metabolism of Streptococcus mutans. Eur J Oral Sci 120:319-325 doi:10.1111/j.16000722.2012.00971.x

Jannasch A, Sedlak M, Adamec JA (2011) Quantification of Pentose Phosphate Pathway (PPP) Metabolites by Liquid Chromatography-Mass Spectrometry (LC-MS). vol 708. Methods in Molecular Biology: Metabolic Profiling. Humana Press doi:10.1007/9781-61737-985-7_9

Jensen ME, Polansky PJ, Schachtele CF (1982) Plaque sampling and telemetry for monitoring acid production on human buccal tooth surfaces. Arch Oral Biol 27:2131

Len AC, Harty DW, Jacques NA (2004) Proteome analysis of Streptococcus mutans metabolic phenotype during acid tolerance. Microbiology 150:1353-1366

Li M, Huang R, Zhou X, Gregory RL (2013) Role of sortase in Streptococcus mutans under the effect of nicotine. Int J Oral Sci 5:206-211 doi:10.1038/ijos.2013.86

Li M, Huang R, Zhou X, Zhang K, Zheng X, Gregory RL (2014) Effect of nicotine on dualspecies biofilms of Streptococcus mutans and Streptococcus sanguinis. FEMS Microbiol Lett 350:125-132 doi:10.1111/1574-6968.12317

Loesche WJ (1986) Role of Streptococcus mutans in human dental decay. Microbiol Rev 50:353-380 
Petersen PE, Bourgeois D, Ogawa H, Estupinan-Day S, Ndiaye C (2005) The global burden of oral diseases and risks to oral health Bulletin of the World Health Organization 83:661-669 doi:/S0042-96862005000900011

Rooban T, Vidya K, Joshua E, Rao A, Ranganathan S, Rao UK, Ranganathan K (2011) Tooth decay in alcohol and tobacco abusers. J Oral Maxillofac Pathol 15:14-21 doi:10.4103/0973-029X.80032

Salem HH, Sandham HJ, Chan KH (1985) Lactate dehydrogenase-deficient mutants of serotype g Streptococcus mutans J Dent Res 64:1191-1194

Senadheera DB et al. (2012) Regulation of bacteriocin production and cell death by the VicRK signaling system in Streptococcus mutans J Bacteriol 194:1307-1316 doi:10.1128/jb.06071-11

Shiroza T, Kuramitsu HK (1988) Sequence analysis of the Streptococcus mutans fructosyltransferase gene and flanking regions J Bacteriol 170:810-816

St Martin EJ, Wittenberger CL (1980) Regulation and function of ammonia-assimilating enzymes in Streptococcus mutans. Infect Immun 28:220-224

Stephan RM (1940) Changes in hydrogen-ion concentration on tooth surfaces and in carious lesions. J Am Dent Assoc 27:718-723

Stephan RM (1944) Intra-oral hydrogen-ion concentration associated with dental caries activity. J Dent Res 23:257-266

Svensater G, Larsson UB, Greif EC, Cvitkovitch DG, Hamilton IR (1997) Acid tolerance response and survival by oral bacteria. Oral Microbiol Immunol 12:266-273

Takahashi N, Nyvad B (2008) Caries ecology revisited: microbial dynamics and the caries process. Caries Res 42:409-418 doi:10.1159/000159604

Takahashi N, Washio J, Mayanagi G (2010) Metabolomics of supragingival plaque and oral bacteria J Dent Res 89:1383-1388 doi:10.1177/0022034510377792

Terleckyj B, Shockman GD (1975) Amino acid requirements of Streptococcus mutans and other oral streptococci. Infect Immun 11:656-664

Tomar SL, Winn DM (1999) Chewing tobacco use and dental caries among U.S. men. J Am Dent Assoc 130:1601-1610

Von Der Fehrfr (1965) Maturation and Remineralization of Enamel. Adv Fluorine Res 21:83-98

Weatherell JA (1975) Composition of dental enamel. Br Med Bull 31:115-119

Wellmann KF (1964) Smoking and Health. On the Report of the Advisory Committee to the Surgeon General of the Public Health Service. Dtsch Med Wochenschr 89:1085-1086

Woodward M, Walker AR (1994) Sugar consumption and dental caries: evidence from 90 countries. Br Dent J 176:297-302 doi:10.1038/sj.bdj.4808437

Xu X, Zhou XD, Wu CD (2011) The tea catechin epigallocatechin gallate suppresses cariogenic virulence factors of Streptococcus mutans. Antimicrob Agents Chemother 55:1229-1236 doi:10.1128/AAC.01016-10

Zeng L, Burne RA (2013) Comprehensive mutational analysis of sucrose-metabolizing pathways in Streptococcus mutans reveals novel roles for the sucrose phosphotransferase system permease J Bacteriol 195:833-843 doi:10.1128/jb.02042-12

Zhou H, Weir MD, Antonucci JM, Schumacher GE, Zhou XD, Xu HH (2014) Evaluation of three-dimensional biofilms on antibacterial bonding agents containing novel 
quaternary ammonium methacrylates. Int J Oral Sci 6:77-86

doi:10.1038/ijos.2014.18 


\section{Figure Legends}

Figure 1. Confocal laser scanning microscopy (CLSM) images of biofilms grown on salivacoated coverslips in different concentrations of nicotine as indicated. Live bacteria were stained green (SYTO 9; left column), dead bacteria were stained red (PI; middle column) and live and dead stain combination (right column). Live and dead bacteria in close proximity to each other appear as yellow or orange. Representative images are shown from at least five randomly selected positions of each sample (different nicotine concentrations: $0,1,2 \mathrm{mg} / \mathrm{ml}$ ).

Figure 2. Scanning electronic microscopy (SEM) analysis of the architecture of biofilms grown for 24 hours and treated with different concentrations of nicotine as indicated. Images were taken at 2,000,5,000,10,000, and 20,000X magnifications (left to right, respectively). Representative images are shown from at least five randomly selected positions of each sample (different nicotine concentrations: $0,1,2 \mathrm{mg} / \mathrm{ml})$.

Figure 3. A: Comparison of metabolic profiles from S. mutans planktonic (black) and biofilm (gray) cells both grown in TSBS without nicotine; B: Comparison of metabolic profiles of $S$. mutans biofilm cells grown in TSBS without nicotine (black) or with $1 \mathrm{mg} / \mathrm{ml}$ of nicotine (gray); C: Comparison of metabolic profiles of S. mutans biofilm cells grown in TSBS without nicotine (black) or with $4 \mathrm{mg} / \mathrm{ml}$ of nicotine (gray); and D: Ratio (fold change) of altered S. mutans metabolites from sucrose-induced biofilms grown in the presence of 1 and $4 \mathrm{mg} / \mathrm{ml}$ nicotine concentrations compared to biofilm grown without nicotine; concentrations were divided by the metabolite concentration of biofilm cells grown without nicotine (represented by horizontal line set at a ratio of 1): black, $1 \mathrm{mg} / \mathrm{ml}$; and white, $4 \mathrm{mg} / \mathrm{ml}$. [G6P: Glucose 6-phosphate, F6P: Fructose 6-phosphate, DHAP: Dihydroxyacetone phosphate, 3PG: 3-Phosphoglycerate, PEP: 
Phosphoenolpyruvate, Pyruvate; 6PG: 6-Phosphogluconate; Acetyl CoA, Succinate, Fumarate and Malate.]

Figure 4. Quantitative RT-PCR (qRT-PCR) assays for gene expression of $S$. mutans grown in $1 \mathrm{mg} / \mathrm{mL}$ nicotine (grey). The black bars represent the control. * $\mathrm{P}<0.05$. 
Table 1. Primers used for quantitative real-time PCR (qPCR) in this study

\begin{tabular}{|c|c|}
\hline Gene Name & Primer Sequence (forward and reverse) \\
\hline \multirow[t]{2}{*}{$16 S r R N A$} & 5'-AGCGTTGTCCGGATTTATTG-3' \\
\hline & 5'-CTACGCATTTCACCGCTACA-3' \\
\hline \multirow[t]{2}{*}{ Idh } & 5'-ACTTCACTTGATACTGCTCGTT-3' \\
\hline & 5'-AACACCAGCTACATTGGCATGA-3' \\
\hline \multirow[t]{2}{*}{$n \operatorname{lm} C$} & 5'-AAACGGCAGTAAGGACAACTTGAC-3' \\
\hline & 5'-CTCCCCTGCTTGTTCAGATTTG-3' \\
\hline \multirow[t]{2}{*}{$f t f$} & 5'-CTGACATAACTACGCCAAAG-3' \\
\hline & 5'-TGCTTAAATTAATACCAGCTTC-3' \\
\hline \multirow[t]{2}{*}{$p t s H$} & 5'-ATTCATGCACGCCCAGCATCT-3' \\
\hline & 5'-GACCAACACCAAGGCTCATAAC-3' \\
\hline \multirow[t]{2}{*}{ ptsI } & 5'-GCTGGTATGTGCGGTGAGATG-3' \\
\hline & 5'-GCGTGATCGGAGAACCGATGT-3' \\
\hline \multirow[t]{2}{*}{ ptsK } & 5'-GGGTGTTCTGATCCAAGGAGAT-3' \\
\hline & 5'-CCTTAACAGCACTGGCTCCATA-3' \\
\hline \multirow[t]{2}{*}{ scrA } & 5'-GATTGCCCTCAGCAGTTGACAT-3' \\
\hline & 5'-GCTGGGAAACTTTGATGGAGAC-3' \\
\hline \multirow[t]{2}{*}{$\operatorname{scr} B$} & 5'-ACAGCCTGTCCTGATTTATAGTC-3' \\
\hline & 5'-CTGGTAACCCAATCCATGAGAC-3' \\
\hline
\end{tabular}


Table 2. Lactate levels in biofilm and planktonic S. mutans cells grown in TSBS in the presence of different nicotine concentrations. ${ }^{\text {a }}$ indicates average and standard deviation. Asterisks indicate significance between biofilm cells without nicotine and with $1 \mathrm{mg} / \mathrm{ml}$ nicotine. @ indicates significance between TSBS with $1 \mathrm{mg} / \mathrm{ml}$ and TSBS with $4 \mathrm{mg} / \mathrm{ml}$ nicotine.

\begin{tabular}{cc}
\hline Different treated cells & Lactate Concentration (ug/g wet weight of cells) \\
\hline Planktonic without nicotine & $199.58 \pm 133.50^{\mathrm{a}}$ \\
Biofilm without nicotine & $214.93 \pm 130.00$ \\
Biofilm with $1 \mathrm{mg} / \mathrm{ml}$ nicotine & $406.55 \pm 175.08^{*}$ \\
Biofilm with $4 \mathrm{mg} / \mathrm{ml}$ nicotine & $196.26 \pm 189.45^{@}$ \\
\hline
\end{tabular}


Without nicotine

$1 \mathrm{mg} / \mathrm{ml}$ nicotine

$2 \mathrm{mg} / \mathrm{ml}$ nicotine

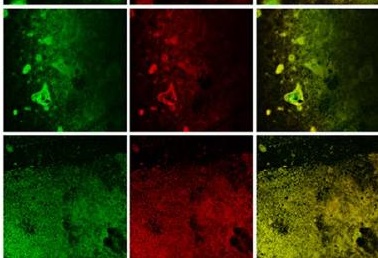




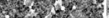

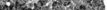
optor. efo tho

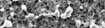
intoris

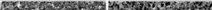
Hexas

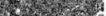

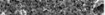
why nesto

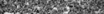

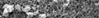

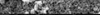

$1 \mathrm{mg} / \mathrm{m}$ nicotine

$2 \mathrm{mg} / \mathrm{ml}$ nicotine

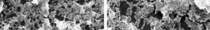

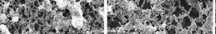

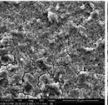

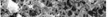

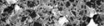
5.20.3.

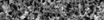

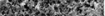

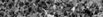

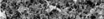
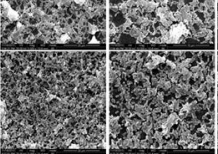

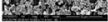
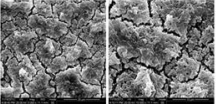

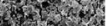

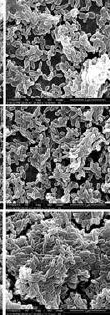


A

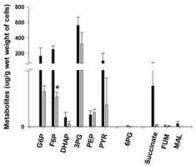

C

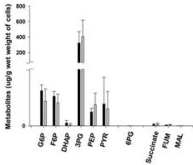

B

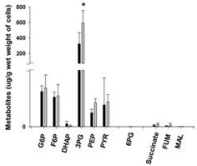

D

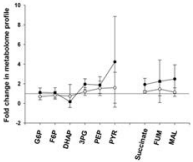


